\title{
Leprosy in the British Solomon Islands.
}

\section{M. Maybury.}

U

NTIL recently, not much notice was taken of leprosy in these islands, and even now, much is mere guesswork, as the number of cases can only be roughly estimated; what seems fairly certain is that the disease is on the increase, judging by the number of children and young folk who are affected.

It may be said that the four hospitals in the group and a Government Travelling Medical Officer carry out the medical work, and at three of these treatment is being given to any cases who come for treatment ; in each case, the work is just a branch of general hospital work. At Fauabu, a part of the Mission land has been set apart for use as a leprosy village, and it is to be run as much like an ordinary village as possible; for the moment, only males can be taken in, but shortly a house will be built for women.

In 1929, there were 42 cases of the disease in the Protectorate diagnosed by medical officers, and this represents only a portion of those infected.

In our colony at Qaibaita, there are at the moment 18 men and children, and this is our limit till more houses are built ; two women have just said that they are willing to come in, and more women will follow the lead taken by these two. With the grant that the British Empire Leprosy Relief Association has given us, a small dispensary will be built, and a small ward for nursing sick cases, as this is so difficult to do in the ordinary native house. Both the buildings will be partly European and partly native.

The whole problem of all the work, and it applies especially to leprosy treatment, is one of transport; this is done by water or by road, and only round the coast is there anything more than a bush track; this practically rules out much out-patient work, even if the lack of staff 
did not do this. We shall have to win the confidence of the people gradually, but the length of treatment is a great stumbling block, as they have got used to the ordinary "needle" and expect results as quickly; their general nature, too, is not one that persists at anything, and they will be lazy if they get the chance. White supervision is needed the whole time, but the staff will not allow of this at present.

The people are only now beginning to isolate cases outside the village, and this chiefly amongst Mission converts. It is an introduced disease, and ignorance and their habits of betal chewing and excessive smoking and interchange of pipes and drinking vessels, makes matters still harder. Those who do realise its gravity of ten get exaggerated ideas of its infectivity, like the white layman in the islands. The people are averse to discipline, and a very strict segregation would only drive many away at present.

I have seen a few nodular cases, but some are badly mutilated, and are of the advanced nerve type. Since the beginning of the year, more are coming forward for treatment ; our numbers are very small compared with other countries, but the population is comparatively small150,000 in all the islands-as far as can be reckoned.

Alepol and moogrol are being used with trichloracetic acid, which to the Melanesian, like the African, is very popular. Various local remedies for the ulcers have been tried, but iodoform in eucalyptus oil is now being used, but it is too early to report results yet.

The work here is at present a sideline from the main hospital, and developed on its own. I feel, however, that when the staff allows and we can travel about in the bush more, more cases will be brought to light. They know that there is no compulsion, and Christians of two denominations and heathen have settled down together. Three $d$ fferent islands are represented; no case is refused admittance to the village, although if he is a hopeless case, the truth is pointed out to him before he comes.

This station has only been in existence for two years and the village for only one year, yet I feel very encouraged.

It may, therefore, be said that the ideal for these islands is voluntary segregation at as many centres as possible, ideally, one on each island, with out-patient facilities for those that live close enough. Travelling in the bush and working with itinerating missionaries would bring us more in contact with sufferers from this disease and lead to a gradual gathering in of the cases. 